\author{
Vasant Chabukswar ${ }^{1}$ and Anjali Athawale ${ }^{2}$
}

\title{
SYNTHESIS AND CHARACTERIZATION STUDIES OF ORGANICALLY SOLUBLE ACRYLIC ACID DOPED POLYDIPHENYLAMINE
}

\author{
${ }^{1}$ Department of Chemistry, N owrosjee Wadia College Pune-411 001, India. \\ vvchabuk@yahoo.com \\ ${ }^{2}$ Department of Chemistry, University of Pune-411 007, India.
}

\author{
Received: April 02, 2008 \\ (C) Chabukswar V., A thawale A. 2008
}

\begin{abstract}
Polydiphenylamine (PDPA) doped with acrylic acid was synthesized by oxidative chemical polymerization. This is a new chemical polymerization method developed for the direct synthesis of emeraldine salt form of polydiphenylamine which exhibits remarkably improved solubility in a common organic solvent. These polymers have been characterized by the physical techniques such as UV-visible, FTIR, XRD and conductivity measurement. The results are discussed with reference to the $\mathrm{H}_{2} \mathrm{SO}_{4}$ doped polydiphenylamine. The use of functionalized acrylic acid (AA) made it possible to obtain the polymer in doped state with enhanced solubility in organic solvent such as N-methyl pyrrolidinone (NMP) and $m$-cresol directly without converting to emeraldine base form. The UV-visible spectra of acrylic acid doped PDPA in $m$-cresol showed a free carrier tail commencing at $950 \mathrm{~nm}$, which may be attributed to secondary doping due to extended coil conformation. Whereas in NMP spectra excitonic peak at $\sim 320 \mathrm{~nm}$ and $610 \mathrm{~nm}$ typical for emeraldine base form indicates that NMP dose hinders the doping ability of dopant. The FTIR spectra shows a broad and intense band at $\sim 3400 \mathrm{~cm}^{-1}$ and $1150-1050 \mathrm{~cm}^{-1}$ in acrylic acid doped PDPA account for the higher doping level than $\mathrm{H}_{2} \mathrm{SO}_{4}$ doped polydiphenylamine polymers. This is further manifested by the X-ray studies and conductivity measurement. The X-ray diffractograms of acrylic acid doped polymer show an enhancement in the crystallinity indicating better ordered chain alignment. These results are well supported by the conductivity measurements, where the conductivity of acrylic acid doped polymers is greater than that of $\mathrm{H}_{2} \mathrm{SO}_{4}$ doped polymers.
\end{abstract}

Key words: polydiphenylamine, functionalized dopant, solubility, crystallinity, conductivity.

\section{Introduction}

The field of conducting polymers has been flourishing rapidly day by day and these materials are becoming indispensable for next century. Many industries are already basing market of their products on conducting polymers [1-3]. Polyaniline and its substituted derivatives have attracted much attention in the recent years because of their electronic, electrochemical, and optical properties and especially because of their proper environment and thermal stability $[2,3]$. These materials have a considerable potential for commercial application in electronics, batteries, solar energy conversion, chemical sensors, corrosion resistance, etc. However, major problems relating to the successful utilization of conducting polymers lies in its poor mechanical properties and processibility due to its insolubility in a common organic solvent. Recently much effort has been made to improve both these aspects [4-7] of route of chemical synthesis method and the use of functional dopant is made more attractive, as it eliminates the use of volatile dopant. More recently, synthetic routes have been developed for polymers by introducing substituents $[7,8]$ or using a functional dopant [9-12]. The incorporation of a functional dopant in electronically conducting polymer is found to enhance its solubility processibility and conductivity that can be attributed to the conformational changes to the polymer chains. Another important chemical modification has been the addition of alkyl, alkoxy or aromatic substituents to the polymer backbone $[4,5]$. This approach has been successfully applied to solubilize the intractable conducting polymer with substituents. These polymers exhibit interesting thermal and morphological properties in the solid state. From the viewpoint of this aspect we have synthesized conducting acrylic acid doped polydiphenylamine, which provides improved electrical and optical as well as solubility and solid state properties. In this paper, the chemical synthesis of novel acrylic acid and $\mathrm{H}_{2} \mathrm{SO}_{4}$ doped polydiphenylamine is described. This reaction is unique, since the polymer obtained has maximum solubility in a common organic solvent directly without the need for a post doping process step, which involves: 
i) neutralization of emeraldine salt to form emeraldine base and ii) secondary doping of the base with a secondary protonic acid. However research has been carried out on structural feature of the acrylic acid doped PDPA in comparison with the doped PDPA.

\section{Experimental}

All chemical used were of analytical reagent grade. The monomer diphenylamine (Qualigens), ammonium persulphate (Qualigens), and $\mathrm{H}_{2} \mathrm{SO}_{4}$ reagent grade (Qualigens) were used as received. Water used in this investigation was double distilled water. General method of synthesis of these conducting polymers involves the chemical oxidation reaction of monomer diphenylamine. The acrylic acid doped polymer was synthesized as in situ oxidative polymerization after addition of $0.4 \mathrm{ml}$ of acrylic acid to the reaction mixture maintained at 273 to $278 \mathrm{~K}$. The $\mathrm{H}_{2} \mathrm{SO}_{4}$ was used as a protonic acid. The monomer to oxidizing agent ratio was kept as 1:1. Ammonium peroxide sulphate solution prepared in double distilled water was added dropwise to the reaction mixture over a period of one hour under constant stirring. After complete addition of the oxidant the reaction was kept under stirring for $24 \mathrm{~h}$. The precipitated polymer salt was recovered from the reaction vessel by filtration and washing followed by drying at 333-343 K for $24 \mathrm{~h}$. A similar procedure was employed for synthesis of polydiphenylamine without acrylic acid media. The synthesized polymers were characterized by using various analytical techniques. UV-visible absorption spectra of these polymers solution in $\mathrm{H}_{2} \mathrm{SO}_{4}, m$-cresol and NMP were recorded on a UV-vis double beam spectrophotometer $(\lambda-20)$ in the range of 300-1000 nm. Fourier-transform infrared spectra (FTIR) of the polymer samples in the range of $400-4000 \mathrm{~cm}^{-1}$ were recorded on a Perking-Elmer 1600 spectrometer. Measurements of wide-angle X-ray diffraction were taken on a Philips X-ray diffractometer using $\mathrm{CuK} \alpha$ radiation source $(\lambda=1.542 \mathrm{~nm})$. The scan range $(2 \theta)$ was $5-50^{\circ}$ and the scanning was performed at the rate of $2^{0} \cdot \mathrm{min}^{-1}$. Conductivity measurements were made on compressed pellets of the powder of the polymer sample using two-probe method at room temperature.

\section{Results and Discussion}

\subsection{Optical Properties of Polymer}

Optical properties have played a key role in the elucidation of the basic electronic structure and solution properties of the conducting polymers. The UV-vis spectra of the polymer doped with acrylic acid and that doped with $\mathrm{H}_{2} \mathrm{SO}_{4}$ were recorded by dissolving these polymers $(5 \% \mathrm{w} / \mathrm{v})$ in $50 \% \mathrm{H}_{2} \mathrm{SO}_{4}, m$-cresol and NMP and are represented in Fig. 1. The spectral features reveal the enhanced solubility of the acrylic acid doped polymer in comparison with the $\mathrm{H}_{2} \mathrm{SO}_{4}$ doped polymer in each solvent. This can be attributed to the presence of greater number of charges on the polymer chain in the acrylic acid doped polydiphenylamine leading to a higher degree of salvation of the polymer due to hydrogen bonding between the solvent and the polymer chains [13-15]. Consequently, the compact coil structure of the polymer would undergo transition to an expanded coil or liner structure [14]. Also, in the presence of a large number of charged centers the electrostatic repulsion between the similar charged units over the polymer chain would be greater in the polymer and it would increases as the distance between the charged units on the polymer chain and its counter ion increases.

Furthermore, one can note that the optical spectra of the polymer show appreciable changes in $50 \% \mathrm{H}_{2} \mathrm{SO}_{4}, m$-cresol and NMP. In $\mathrm{H}_{2} \mathrm{SO}_{4}$ solvent (Fig. 1a) acrylic acid doped polymer exhibits a sharp

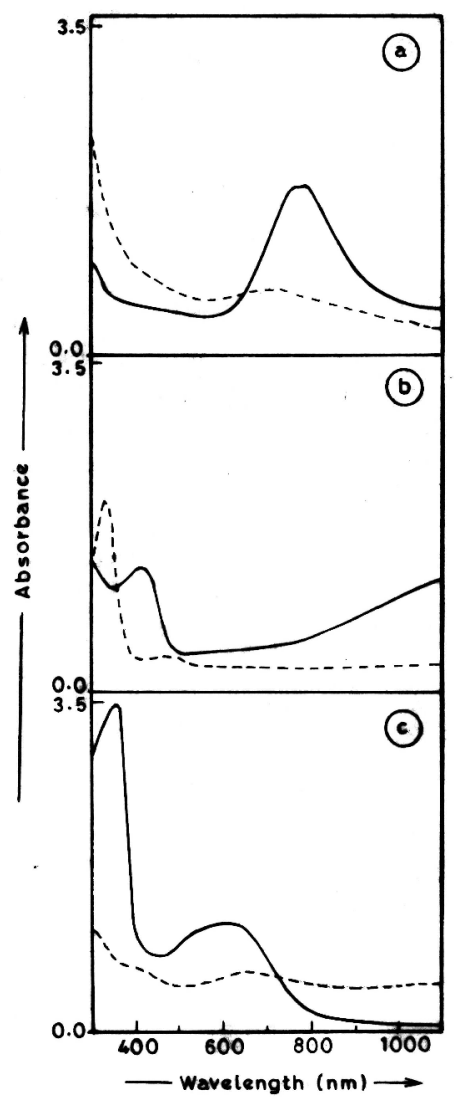

Fig. 1. UV-visible spectra of polydiphenylamine doped in acrylic acid (-) and $\mathrm{H}_{2} \mathrm{SO}_{4}(---)$ : $\mathrm{H}_{2} \mathrm{SO}_{4}$ media (a); $m$-cresol media (b) and NMP media (c) 
peak $\sim 700 \mathrm{~nm}$ representing the conducting emeraldine salt phase of the polymer. The shoulder at $\sim 320$ and $420 \mathrm{~nm}$ corresponds to the electronic transition within the benzenoid segment and the protonation of polydiphenylamine polymer chains respectively [15-17]. The overall peak intensity of the $\mathrm{H}_{2} \mathrm{SO}_{4}$ doped polymer is less than acrylic acid doped PDPA, which accounts for the presence of greater fraction of quinoid phase form indicating the presence of mixed phases. The spectral nature is found to differ when spectra was compared in different organic solvent implying the influence of solvent on the polymer properties as seen in Fig. $1 \mathrm{~b}$.

In $m$-cresol solvent, the acrylic acid doped polymer exhibits a shoulder $\sim 320 \mathrm{~nm}$ and a broad intense peak $\sim 415 \mathrm{~nm}$ with an extended free carrier tail characteristic of an extended coil conformation with increasing absorbance $~ 800-1000 \mathrm{~nm}$ [14-17]. The shoulder $\sim 320 \mathrm{~nm}$ is typical for the transition of the benzene ring, while the sharp intense peak $\sim 415 \mathrm{~nm}$ corresponds to the localized polarons which are characteristic of the protonated emeraldine salt form. The presence of free carrier tail absorption indicates that the polymer backbone adopts an expanded conformation allowing increased conjugation. It is observed that doping of acrylic acid doped PDPA is more efficient in $m$-cresol than $\mathrm{H}_{2} \mathrm{SO}_{4}$ doped PDPA. Further, the extended tail at higher wavelength depicts that $m$-cresol not only serves as a solvent but also as an efficient secondary dopant $[15,16]$. In comparison with the absorption spectra of acrylic acid doped PDPA, the intensity of the peak at $\sim 313$ and $\sim 800 \mathrm{~nm}$ of $\mathrm{H}_{2} \mathrm{SO}_{4}$ doped PDPA are significantly lower. This can probably be attributed to the lower doping level and the lower electron density in the polymer backbone. The optical absorptions of these polymers are also varied by the change of the solvent system. Fig. 1c shows the UVvisible spectra of acrylic acid and $\mathrm{H}_{2} \mathrm{SO}_{4}$ doped PDPA in NMP solvent. In the presence of NMP solvent the absorption maximum at $\sim 850 \mathrm{~nm}$ along with free carrier tail absorption and $\sim 420 \mathrm{~nm}$ (polaron peak) is seen to disappear while a sharp peak is observed: $\sim 620 \mathrm{~nm}$ and $\sim 320 \mathrm{~nm}$. The absorption at $\sim 322 \mathrm{~nm}$ is ascribed to the transition of the benzonoid rings at $\sim 600 \mathrm{~nm}$, which is assigned to exciton absorption of the quinoid rings. This reflects the solvent effect on the polymer properties. NMP is a highly polar solvent $(\varepsilon=32)$, so the solvent-solute interaction would be stronger than that in $m$-cresol medium. The $\mathrm{C}=\mathrm{O}$ group present in NMP molecule would try to form a hydrogen bond with the $\mathrm{H}$ of the $\mathrm{COOH}$ group of dopant or those present the $\mathrm{N}$ atoms of the polymer chain. This, in turn, would bring about deprotonation of the polymer chain resulting in the conversion of conducting salt phase into insulating emeraldine base form of the polymer in addition to the coiling up of the polymer chain. Therefore, one observes a sharp peak at $\sim 600 \mathrm{~nm}$, while the peak representing the polarons is weaker along with the weak absorbance at higher wavelength [12-15].

\subsection{FTIR Spectra}

The infrared spectra of $\mathrm{H}_{2} \mathrm{SO}_{4}$ and acrylic acid doped polymers are shown in Fig. 2 and the peak locations related to corresponding chemical bonds are summarized in Table 1. However, a remarkable difference is observed in the spectra in terms of specific bonds and shifts in the two polymers. The key bands in salt form match well with those reported in the literature [15-20]. The broad and intense band at $~ 3400$ $3300 \mathrm{~cm}^{-1}$ with a shoulder around $2920 \mathrm{~cm}^{-1}$ and $\sim 1170$, $1000 \mathrm{~cm}^{-1}$ in acrylic acid doped polymer accounts for the higher degree of doping and protonation of amine and imine nitrogens [16-18]. Interestingly, the peak intensities at $\sim 1025 \mathrm{~cm}^{-1}$ and $\sim 630 \mathrm{~cm}^{-1}$ increase in the acrylic acid doped polymer, which confirms that acrylic acid doped polymer were effectively doped by dopant than $\mathrm{H}_{2} \mathrm{SO}_{4}$ doped PDPA. These bands appearing in $\mathrm{H}_{2} \mathrm{SO}_{4}$ doped PDPA become relatively sharp and narrow indicating lower degree of protonation and doping [1920]. However, both of the polymers exist in conductive form. This can be attributed to breaking up of a large number of inter-chain hydrogen bonds that arise due to the addition of acrylic acid since it acts as pseudoprotonic acid dopant and coordinates with the imine $\mathrm{N}-$ atom of the polymer chain [17-20]. Stronger mutual interaction between the functional dopant and polymer may allow the two polymer chains to have their positions in space closer to each other and to result in more efficient doping of the PDPA. This leads to disaggregation of the polymer chains and hence the expanded coil structure and crystallinity. Moreover, the absorption band clearly observed in acrylic acid doped PDPA ranging at $\sim 2500 \mathrm{~cm}^{-1}$ are assigned to the vibration associated with stretching vibration of protonated amine and imine $\mathrm{N}$ atoms [19-20]. These are relatively weak in doped PDPA polymer. In addition to this, the acrylic acid doped polymer shows a peak $\sim 1620 \mathrm{~cm}^{-1}$ in which there could be convolution of a bending vibration of the water molecule and the asymmetrical stretching of the carboxylate group (-COO) resulting from the acid base reaction between acrylic acid and polymer. The interaction bands at 1238 and $1415 \mathrm{~cm}^{-1}$ for $\mathrm{C}-\mathrm{O}$ stretching and $\mathrm{C}-\mathrm{OH}$ in plane bending reveal the presence of free acrylic acid in the polymer matrix. Strong bands due to different stretching modes of benzene rings are located at 1595 and $1500 \mathrm{~cm}^{-1}$ in $\mathrm{H}_{2} \mathrm{SO}_{4}$ doped PDPA polymer. Furthermore, in acrylic acid doped PDPA these bands are seen to be broadened and shifted to lower wave number: 1558 and $1492 \mathrm{~cm}^{-1}$. The bands at $\sim 1300$ 
and $\sim 1250 \mathrm{~cm}^{-1}$ are attributed to the $\mathrm{C}-\mathrm{N}$ stretching and deformation modes of the aromatic amine respectively [18-20]. The symmetric stretching vibrations of $S=0$ groups appear between 1170$1028 \mathrm{~cm}^{-1}$. The asymmetric stretching of $\mathrm{S}=0$ group $\left(\sim 1300,1320 \mathrm{~cm}^{-1}\right)$ may overlap with the characteristic $-\mathrm{N}$ stretching vibration. In acrylic acid doped PDPA the intensity of these bands is high and the presence of these bands is ascribed to the higher doping level because of the strong electrostatic interaction between dopant and polymer. The presence of strong absorption peaks at $\sim 810 \mathrm{~cm}^{-1}$ is assigned to a 4-substituted phenyl group compared to the low intensity of the peak at 743 and $\sim 692 \mathrm{~cm}^{-1}$ due to the terminal phenyl groups. This indicates that polymers were obtained through the 4, 4 C-C phenyl coupling of monomer unit [21].
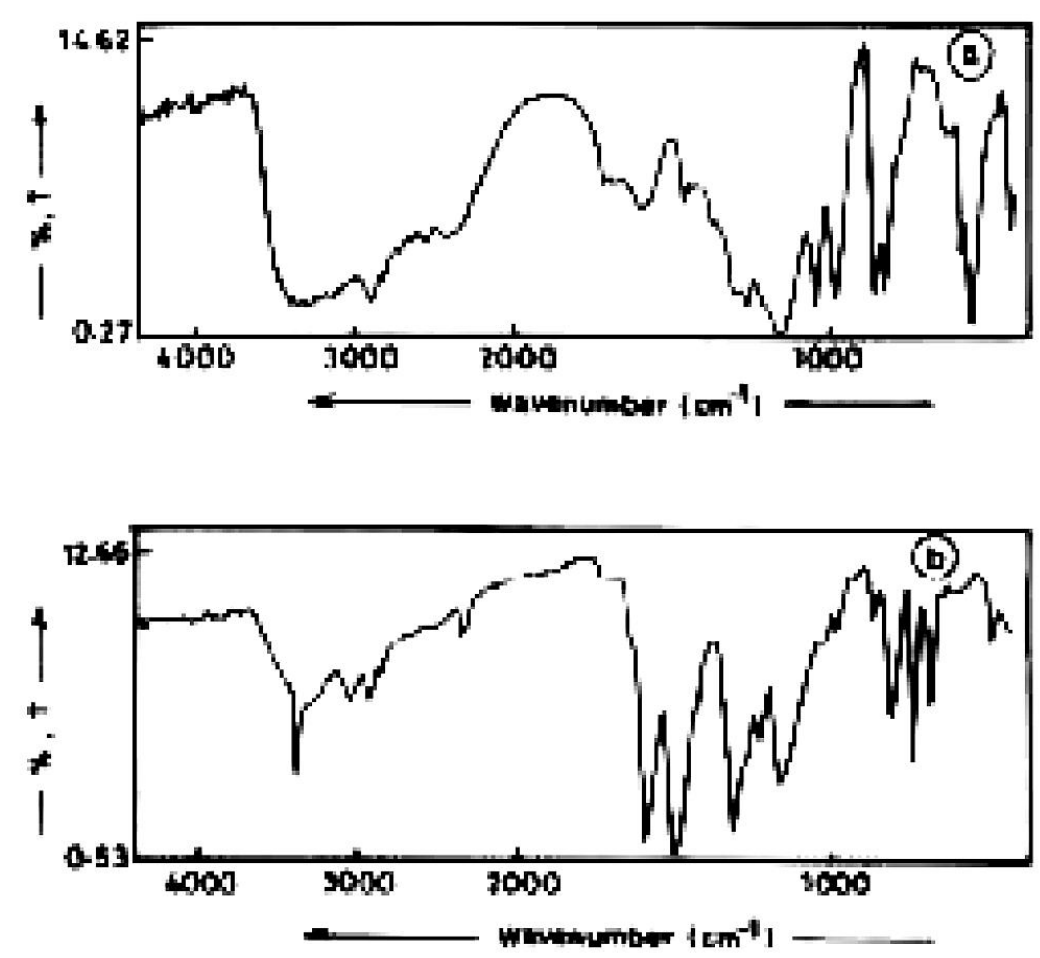

Fig. 2. FTIR absorption spectra of acrylic acid (a) and $\mathrm{H}_{2} \mathrm{SO}_{4}$ doped PDPA (b)

FTIR spectral data of polydiphenylamine doped in acrylic acid and $\mathrm{H}_{2} \mathrm{SO}_{4}$ media

\begin{tabular}{|c|c|l|}
\hline PDPA/AA & PDPA/H2 SO4 & \multicolumn{1}{c|}{ Peak Assignment } \\
\hline $710-743$ & $627-748$ & Out of plane C-H bending vibration \\
\hline 850 & 821 & Para-disubstituted benzene ring \\
\hline 1008,1060 & 1028,1037 & Vibration band of dopand anion \\
\hline 1173 & 1173 & B N H B stretching vibration \\
\hline 1285 & - & (-COO) stretching band \\
\hline 1322 & 1317 & Aromatic $(\mathrm{C}-\mathrm{N})$ stretching band \\
\hline 1493 & 1504 & Benzenoid ring stretching band \\
\hline 1590 & 1595 & Quinoid ring stretching band \\
\hline Broad 1620 & - & - - $(-$ COO) asymmetrical stretching band \\
\hline 1743 & - & Carbonyl $(-\mathrm{C}=$ O) stretching band \\
\hline 2920 & 2921 & C-H stretching band \\
\hline 3404 & 3386 & N-H stretching band \\
\hline
\end{tabular}



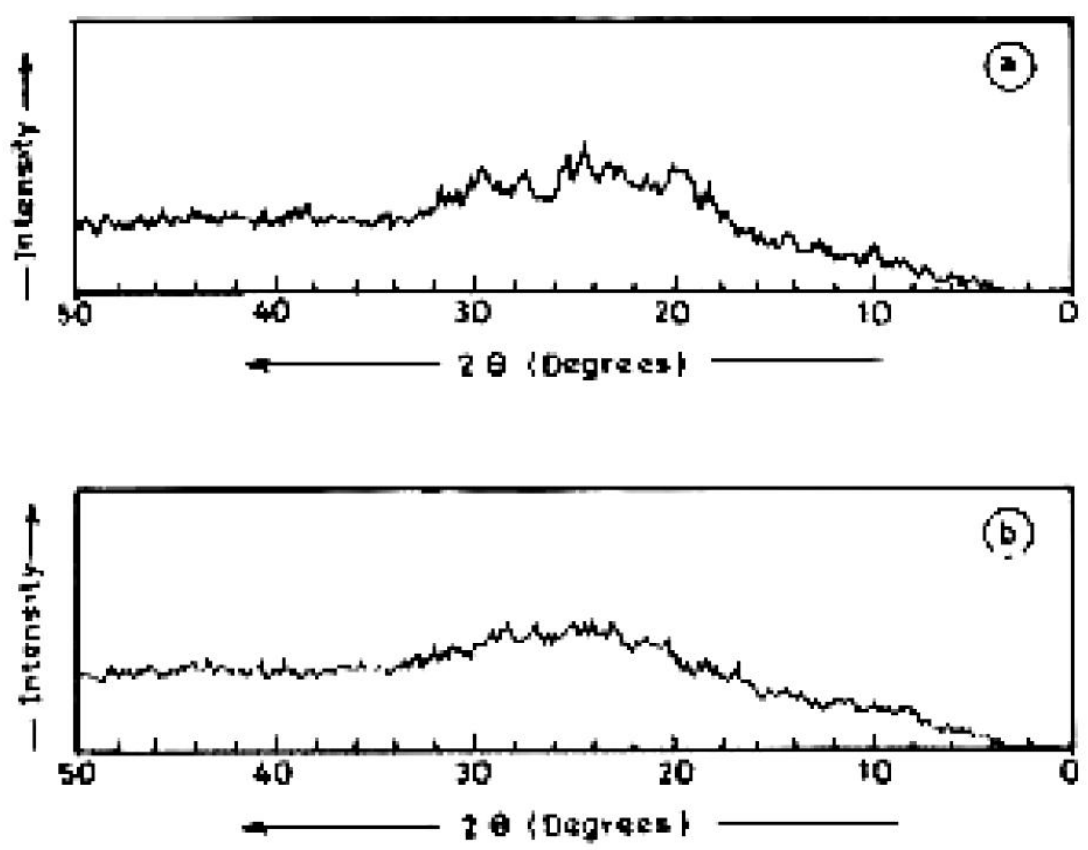

Fig. 3. X-ray diffraction patterns of acrylic acid (a) and $\mathrm{H}_{2} \mathrm{SO}_{4}$ doped PDPA (b)

\subsection{X-ray Diffraction Studies}

Fig. 3 shows the X-ray diffraction pattern of the acrylic acid and $\mathrm{H}_{2} \mathrm{SO}_{4}$ doped PDPA. As seen from Fig. 3, $\mathrm{H}_{2} \mathrm{SO}_{4}$ doped PDPA sample showed broadening pattern indicating the amorphous nature of polymer, due to short range order [19-22]. However several sharp peaks are observed in acrylic acid doped PDPA polymer at $2 \theta$ of $14,18,19.8,21,22,23,24,25,27,29,30,38$ indicating the presence of a rigid chain and ordered structure resulting in partial crystallinity [16-21]. It is interesting to note that the degree of crystallinity in acrylic acid doped polymer is greater than the $\mathrm{H}_{2} \mathrm{SO}_{4}$ doped polymer as observed from the intensity of the peaks which is consistent with the conformational changes of the polymer chain in acrylic acid doped polymer together with the increased sharpness in the amorphous scattering at $2 \theta$ of 20 [19, 22-24].

\subsection{Electrical Conductivity}

These results are well supported by the conductivity data obtained for the both polymers. Acrylic acid doped PDPA polymer exhibits higher conductivity $\left(4.5 \cdot 10^{-2} \mathrm{~S} \cdot \mathrm{cm}^{-1}\right)$ compared to $\mathrm{H}_{2} \mathrm{SO}_{4}$ doped PDPA polymer $\left(7.6 \cdot 10^{-3} \mathrm{~S} \cdot \mathrm{cm}^{-1}\right)$. This can be attributed to the presence of large concentration of $\mathrm{COO}$ ions serving as a functional dopant along with few $\mathrm{H}_{2} \mathrm{SO}_{4}$ doped sites and trapped $\mathrm{COOH}$ molecules present in the polymer matrix. In addition, it has been suggested that the functional dopant counter anion is capable of enhancing conductivity [22-25]. Chen and Lee have reported the results on the polyacrylic acid doped polyaniline blend having a conductivity of $\sim 2.9 \cdot 10^{4} \mathrm{~S} \cdot \mathrm{cm}^{-1}$. The polymer synthesized in the present case exhibits a conductivity higher than that reported by them [26-27].

\section{Conclusions}

Acrylic acid and $\mathrm{H}_{2} \mathrm{SO}_{4}$ doped polydiphenylamine PDPA were synthesized by chemical oxidative polymerization. The reaction is unique which yields a truly soluble conducting emeraldine salt directly without the need for a postdoping process step. This was an easy and scalable one-step method to produce PDPA in its conductive state. In addition to the solubilizing effect, this dopant gives better crystallinity and conductivity. The conductivity differences between acrylic acid doped and $\mathrm{H}_{2} \mathrm{SO}_{4}$ doped PDPA may occur due to stronger mutual interaction between the functional acid dopant and the polymer, which may allow the two polymer chains to have their position in space closer to each other and result in more efficient doping of the polymer. These observations imply that there is a correlation between the functionality of dopant counter anion and the solid state polymer properties.

\section{Acknowledgements}

One of the author, Dr. Vasant V. Chabukswar, is thankful to Indian Academy of Sciences (IAS) and Material Research Society of India (MRSI), Bangalore for awarding the summer research fellowship and Indian 
National Science Association (INSA) and University of Pune for financial assistance. We thank to Nowrosjee Wadia College and University of Pune, India, for awarding the teacher fellowship.

\section{References}

[1] Inganas B., Gustafsson G., Gustafsson-Carlberg J. et al.: Nature, 1994, 372, 444.

[2] Genies E. and Lapkowski M.: Synth. Met., 1988, 24, 61.

[3] Chen S. and Fang W.: Macromolecules, 1991, 24, 1242.

[4] Dao Le H., Nguyen My T. and Paynter R.: Synth. Met., 199, 41-43, 649.

[5] MacDiarmid A., Armes P., Winter J. et al.: Polymer, 1993, 34, 158.

[6] Bagheri A., Nateghi M. and Massoumi A.: Synth. Met, 1998, 97, 85 .

[7] Roy B., Dutta Gupta M., Bhowmik L. and Ray J.: Synth. Met., 1999, 100, 233.

[8] Gabriel A., Gustavo M., Miras M. and Barbero C.: Synth. Met., 1998, 97, 223.

[9] Moon Soo and Park H.: Synth., Met., 1998, 92, 233.

[10] Chen S. and Lee H.: Synth. Met., 1989, 29, E271.

[11] Hwang J. and Yang S.: Synth. Met., ibid.

[12] Santos J., Malmonge J., Conceicao Silva A. et al.: Synth. Met., 1995, 69, 141.

[13] Zheng W., Min Y., MacDiarmid A. et al.: Synth. Met., 1997, 84, 109.

[14] Zheng W., Angelopoulos M., Epstein A. and MacDiarmid A.: Macromolecules, 1997, 24, 7634.

[15] MacDiarmid A. and Epstein A.: Synth. Met., 1994, 65, 103. [16] Anilkumar P. and Jaykannan M.: Langmuir, 2006, 69, 85. [17] Paul R., Vijayan M. and Pillai C.: Synth. Met., 1999, 104, 189. [18] Ogura K., Saino T., Nakayama M. and Shigi H.: J. Mater. Chem., 1997, 7, 2363.
[19] Yoo J., Cross J., Bucholz T. et al.: J. Mater. Chem., 2007, 17, 1268.

[20] He Y. and Yu X.: Mater. Lett., 2007, 61, 2071.

[21] Elothmani D., Guillanton G. and Simonet J.: Eur. Polym. J., 1996, 32, 1 .

[22] Li Xiaoxuan and Li Xingwei: Mater. Lett., 2007, 61, 2011. [23] Moon HyukSoo and Park Jung-Ki: Synth. Met., 1998, 92, 223.

[24] Moon HyukSoo and Park Jung-Ki: J. Polymer Sci. Part A., 1998, 36, 1431.

[25] Chabukswar V. and Athawale A.: J. Appl. Polymer Sci., 2001, 79, 1994.

[26] Chen S. and Lee H.: Macromolecules, 1993, 26, 3254.

[27] Chen S. and Lee H.: Macromolecules, 1995, 28, 2858.

\section{СИНТЕЗ І ХАРАКТЕРИСТИКА ОРГАНІЧНО РОЗЧИННОГО ПОЛІДИФЕНІЛАМІНУ 3 ДОДАТКОМ АКРИЛОВОї КИСЛОТИ}

Анотація. Окислювальною хімічною полімеризацію $з$ використанням невеликої кількості акрилової кислоти синтезовано полідифеніламін (ПДФА). Запропонований новий метод хімічної полімеризаиії може бути використаний для керованого синтезу солевих форм ПДФА, які здатні розчинятися у звичайних органічних розчинниках. Отримані полімери охарактеризовані фізичними методами, зокрема УФ-, Фур 'є-спектроскопією, рентген-дослідженнями, а також вимірюванням провідності. Використання функиійной акрилової кислоти дозволило отримувати полімер 3 підвищеною розчинністю в таких органічних розчинниках, як $N$-метил піролідон і м-крезол без перетворення в основну форму емеральдину.

Ключові слова: полідифеніламін, функиійний додаток, розчинність, кристалічність, електропровідність. 